\title{
Article \\ Oxidative Stress, Glutathione Metabolism, and Liver Regeneration Pathways Are Activated in Hereditary Tyrosinemia Type 1 Mice upon Short-Term Nitisinone Discontinuation
}

\author{
Haaike Colemonts-Vroninks ${ }^{1}{ }^{(}$, Jessie Neuckermans ${ }^{1}$, Lionel Marcelis ${ }^{2}{ }^{\circledR}$, Paul Claes ${ }^{1}$, Steven Branson ${ }^{1}$, \\ Georges Casimir ${ }^{2}$, Philippe Goyens ${ }^{2}$, Geert A. Martens ${ }^{3,4}$, Tamara Vanhaecke ${ }^{1}\left(\mathbb{D}\right.$ and Joery De Kock ${ }^{1, *(\mathbb{D})}$ \\ 1 Department of In Vitro Toxicology and Dermato-Cosmetology (IVTD), Vrije Universiteit Brussel (VUB), \\ Laarbeeklaan 103, 1090 Brussels, Belgium; haaike.colemonts-vroninks@vub.be (H.C.-V.); \\ Jessie.Neuckermans@vub.be (J.N.); Paul.Claes@vub.be (P.C.); Steven.Branson@vub.be (S.B.); \\ Tamara.Vanhaecke@vub.be (T.V.) \\ 2 Laboratoire de Pédiatrie, Hôpital Universitaire des Enfants Reine Fabiola (HUDERF), Université Libre de \\ Bruxelles (ULB), Avenue J.J. Crocq 1-3, 1020 Brussels, Belgium; Lionel.MARCELIS@huderf.be (L.M.); \\ georges.casimir@huderf.be (G.C.); pgoyens@ulb.ac.be (P.G.) \\ 3 Department of Laboratory Medicine, AZ Delta General Hospital, Deltalaan 1, 8800 Roeselare, Belgium; \\ Geert.Martens@azdelta.be \\ 4 Center for Beta Cell Therapy in Diabetes, Vrije Universiteit Brussel (VUB), Laarbeeklaan 103, \\ 1090 Brussels, Belgium \\ * Correspondence: Joery.De.Kock@vub.be; Tel.: +32-2-477-4517; Fax: +32-2-477-4582
}

\section{check for}

updates

Citation: Colemonts-Vroninks, H.; Neuckermans, J.; Marcelis, L.; Claes, P.; Branson, S.; Casimir, G.; Goyens, P.; Martens, G.A.; Vanhaecke, T.; De Kock, J. Oxidative Stress, Glutathione Metabolism, and Liver Regeneration Pathways Are Activated in Hereditary Tyrosinemia Type 1 Mice upon ShortTerm Nitisinone Discontinuation. Genes 2021, 12, 3. https://dx.doi.org/10.3390/ genes12010003

Received: 17 November 2020 Accepted: 18 December 2020 Published: 22 December 2020

Publisher's Note: MDPI stays neutral with regard to jurisdictional claims in published maps and institutional affiliations.

Copyright: (c) 2020 by the authors. Licensee MDPI, Basel, Switzerland. This article is an open access article distributed under the terms and conditions of the Creative Commons Attribution (CC BY) license (https: / / creativecommons.org/ licenses/by/4.0/).
Abstract: Hereditary tyrosinemia type 1 (HT1) is an inherited condition in which the body is unable to break down the amino acid tyrosine due to mutations in the fumarylacetoacetate hydrolase (FAH) gene, coding for the final enzyme of the tyrosine degradation pathway. As a consequence, HT1 patients accumulate toxic tyrosine derivatives causing severe liver damage. Since its introduction, the drug nitisinone (NTBC) has offered a life-saving treatment that inhibits the upstream enzyme 4-hydroxyphenylpyruvate dioxygenase (HPD), thereby preventing production of downstream toxic metabolites. However, HT1 patients under NTBC therapy remain unable to degrade tyrosine. To control the disease and side-effects of the drug, HT1 patients need to take NTBC as an adjunct to a lifelong tyrosine and phenylalanine restricted diet. As a consequence of this strict therapeutic regime, drug compliance issues can arise with significant influence on patient health. In this study, we investigated the molecular impact of short-term NTBC therapy discontinuation on liver tissue of Fah-deficient mice. We found that after seven days of NTBC withdrawal, molecular pathways related to oxidative stress, glutathione metabolism, and liver regeneration were mostly affected. More specifically, NRF2-mediated oxidative stress response and several toxicological gene classes related to reactive oxygen species metabolism were significantly modulated. We observed that the expression of several key glutathione metabolism related genes including Slc7a11 and Ggt1 was highly increased after short-term NTBC therapy deprivation. This stress response was associated with the transcriptional activation of several markers of liver progenitor cells including Atf3, Cyr61, Ddr1, Epcam, Elovl7, and Glis3, indicating a concreted activation of liver regeneration early after NTBC withdrawal.

Keywords: hereditary liver disease; tyrosinemia type 1; nitisinone; transcriptomics; oxidative stress; glutathione metabolism; liver regeneration

\section{Introduction}

Hereditary tyrosinemia type 1 (HT1, OMIM \#276700) is the most prevalent and severe of the five tyrosine-related inherited metabolic disorders (TIMD). The overall incidence of this rare autosomal recessive disease is estimated at 1 in 100,000 newborns worldwide [1]. 
However, significantly larger numbers of new patients have been reported in specific regions including the province of Quebec, Canada and Northern Europe, i.e., Finland and Norway [2-5]. HT1 is characterized by a defective or absent fumarylacetoacetate hydrolase (FAH) enzyme, the final enzyme of the tyrosine degradation pathway that is predominantly active in liver and kidney cells (Figure 1) [6,7]. It manifests as a severe necrotic liver disease accompanied by hepatomegaly, cirrhosis, impaired coagulation, acute-on-chronic liver failure resulting in jaundice, ascites, bleeding and neurological crises $[1,6]$. This chronic liver injury likewise increases the risk for hepatocellular carcinoma (HCC) development. HT1 also affects normal kidney function causing renal tubular defects with rickets, Fanconi-like syndrome and glomerulosclerosis [8]. The damage to the liver and kidneys is caused by the accumulation of toxic upstream metabolites fumarylacetoacetate and maleylacetoacetate that cause protein denaturation (Figure 1) [1,9]. These toxic intermediates are downstream metabolized into toxic derivatives succinylacetoacetate and succinylacetone (SA) which play a major role in the onset of neurological crises (Figure 1) [10]. Without proper and early treatment, HT1 can present itself under three main clinical forms: (i) The acute form, which is associated with acute liver failure during the first months of life, failure to thrive and, in most cases, death of the patients in their infancy; (ii) the subacute form that usually appears within the second half of the first year after birth as hepatomegaly and rickets due to renal tubular defects; and (iii) the chronic form which presents after the first year of age and shows slower disease progression [11].

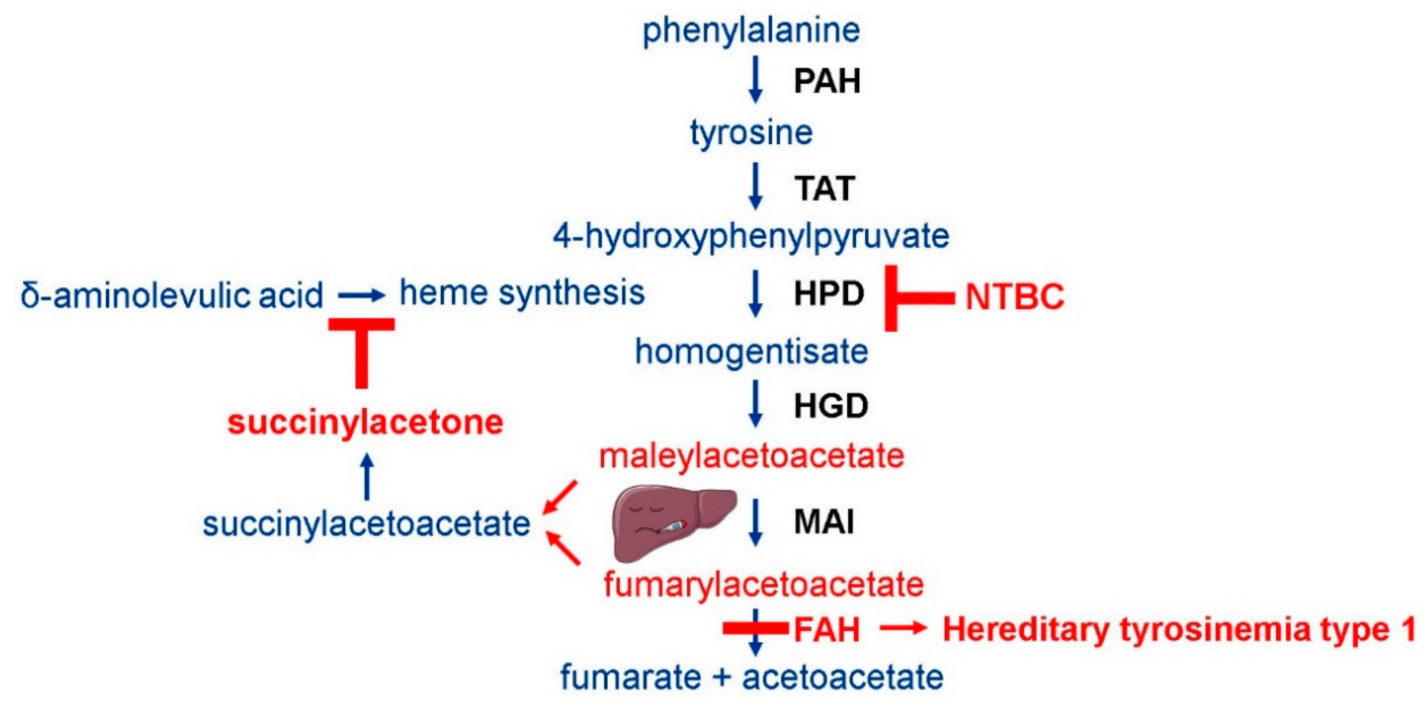

Figure 1. Tyrosine degradation pathway in liver cells. Loss of function of the fumarylacetoacetate hydrolase (FAH) enzyme causes the accumulation of toxic intermediate tyrosine metabolites maleyl- and fumarylacetoacetate, and subsequently, the production of succinylacetone through an alternative metabolization route. Nitisinone (NTBC) is a potent inhibitor of the upstream hydroxyphenylpyruvate dioxygenase (HPD) enzyme that prevents the formation of these toxic metabolites by providing a therapeutic block. Abbreviations: PAH, phenylalanine hydroxylase; TAT, tyrosine aminotransferase; HPD, 4- hydroxyphenylpyruvate dioxygenase; HGD, homogentisate dioxygenase; MAI, maleylacetoacetate isomerase; FAH, fumarylacetoacetate hydrolase, NTBC, nitisinone.

Historically, tyrosine- and phenylalanine-restricted diets have been applied as therapy for HT1 patients, but have proven to be inadequate, especially in case of acute and subacute clinical forms $[12,13]$. Orthotopic liver transplantation is being applied, but only for those patients that suffer from acute-on-chronic liver failure or that have developed HCC due to a delayed diagnosis as a result of inadequate neonatal screening programs [14-16]. For more than twenty years, standard therapy for HT1 patients consists of the lifelong daily intake of the drug NTBC (2-(2-nitro-4-trifluoromethylbenzoyl)-1,3-cyclohexanedione; nitisinone), a former herbicide and potent inhibitor of the key enzyme 4-hydroxyphenylpyruvate dioxygenase (HPD) [17,18]. NTBC therapy causes an effective upstream metabolic block that 
prevents the production of the aforementioned toxic metabolites (Figure 1) [2]. However, although NTBC therapy rescues HT1 patients from severe illness and early death, it also leads to tyrosine accumulation in the blood [19], the production of alternative tyrosinederivatives including $\mathrm{N}$-acetyltyrosine [20], the disturbance of monoamine neurotransmitter metabolism [21,22], and the symbiotic perturbation of host and microbiome tryptophan metabolism [23]. Noteworthy changes are also present in the ratio of several amino acids suggesting that the availability of amino acids for neurotransmitter biosynthesis and liver function may be altered [22]. Due to the aforementioned effects of NTBC therapy, concerns exist for patients to develop ocular, cutaneous and possible neurological complications including mood changes, lower IQ and depression as observed in hereditary tyrosinemia type 2 (HT2,OMIM \#276600) and type 3 (HT3, OMIM \#276710) patients as a consequence of hypertyrosinemia [24-26]. Corneal keratopathy, with the risk of developing blindness, has been detected even with low dose NTBC in TIMD patients [27]. NTBC therapy, due to the concomitant hypertyrosinemia, requires therefore lifelong dietary adjustment by a tyrosine- and phenylalanine-restricted diet in order to reduce the debilitating side-effects of the drug. Unfortunately, due to this strict therapeutic regime, drug compliance issues could become a problem for HT1 patients with significant impact on their health.

To gain fundamental knowledge on the impact of non-drug compliance, we investigated which molecular mechanisms and pathways become modulated in the liver as soon as the inhibitory effects of the drug NTBC become less effective. To accomplish this, we performed gene expression profiling and biochemical analyses of Fah-deficient mouse livers under continuous NTBC therapy and after seven days of NTBC therapy discontinuation.

\section{Materials and Methods}

\subsection{Tyrosinemia Type 1 Mouse Model}

The FRG mouse model (C57Bl/6J background; Yecuris) is characterized by a triple knockout of $\mathrm{Fah}^{-/-}$, Rag2 ${ }^{-/-}$, and Il2 $\mathrm{rg}^{-/-}$and thus serves as a suitable model for HT1. Neonates die from acute liver failure if NTBC is not continuously administered [28]. Therefore, unless specified otherwise, all mice received continuous NTBC treatment $(16 \mathrm{mg} / \mathrm{L})$ through their drinking water, supplemented with 3\% $(w / v)$ dextrose for taste. Mice were fed with irradiated LabDiet ${ }^{\circledR}$ 5LJ5 chow (LabDiet, St. Louis, MO, United States) ad libitum, which is a low-tyrosine and low-phenylalanine diet that acts as a surrogate for the protein-restricted diet of HT1 patients.

\subsection{Animal Experiments}

All mouse caring, breeding and experimental procedures were performed in accordance with the ethical standards of the Vrije Universiteit Brussel and National Rules on Animal Experimentation and were approved under grant numbers 15-210-2 and 15-210-4 by the local Ethical Committee for Animal Experiments of the Vrije Universiteit Brussel in Belgium. Mice were group-housed in individual ventilated cages (IVC) in a temperature $\left(19-23^{\circ} \mathrm{C}\right)$ and humidity (30-70\% relative humidity) regulated environment with a $14 / 10-\mathrm{h}$ light/dark cycle under continuous NTBC treatment $(16 \mathrm{mg} / \mathrm{L})$ administered through their drinking water. Cage environment was enriched with cardboard shelters, nesting material and wooden sticks. To the best of our abilities, results were reported in accordance with the ARRIVE guidelines [29]. At the age of 11 weeks, NTBC therapy was discontinued for seven consecutive days for the FRG-7dNTBC group whereas it was administered continuously for the FRG+NTBC group.

\subsection{Sample Collection and Preparation}

At the age of 12 weeks, all mice were anesthetized by intraperitoneal injection of ketamine/xylazine mixture $\left(87.5 \mathrm{mg} / \mathrm{kg}\right.$ Ketamidor $^{\circledR}$ (Ecuphar BV, Breda, The Netherlands)/12.5 mg/kg Rompun ${ }^{\circledR}$ (Bayer Animal Health GmbH, Leverkusen, Germany)). Blood samples were collected by a ventral heart puncture with a $26 \mathrm{Gx}{ }^{1 / 2^{\prime \prime}}$ needle $(0.45 \times 13 \mathrm{~mm})$ and $1 \mathrm{~mL}$ syringe (Terumo; ${ }^{\circledR}$ VWR, Leuven, Belgium). 
Between $0.5-1 \mathrm{~mL}$ of blood was collected in ethylenediaminetetraacetic acid (EDTA) coated micro tubes (Sarstedt, Nümbrecht, Germany, K3E tube) together with 1-2 drops of blood on dried blood spot (DBS) cards (Whatman, Overijse, Belgium, 903; GE Healthcare). DBS cards were allowed to dry at room temperature for at least $24 \mathrm{~h}$ before use. Blood samples were centrifuged $\left(1500 \times g, 15 \mathrm{~min}\right.$ and $\left.4{ }^{\circ} \mathrm{C}\right)$ and serum was frozen at $-80^{\circ} \mathrm{C}$ until further use. DBS cards were analyzed as described below within 1 month post collection. Liver tissue was collected and rinsed with ice cold physiological serum to remove remaining debris. Liver tissue cubes of approximately $1-2 \mathrm{~cm}^{3}$ were fixed at $4{ }^{\circ} \mathrm{C}$ in $4 \%(w / v)$ paraformaldehyde (Sigma-Aldrich, Overijse, Belgium) for $24 \mathrm{~h}$, dehydrated in ethanol (VWR, Leuven, Belgium) series (using Microm GmbH STP 120-1, Prosan, Arnhem, The Netherlands) and embedded in paraffin (using Microm EC 350-1, Prosan) for histopathological analyses. For protein and transcriptome analysis, liver tissue cubes of max. $1 \mathrm{~cm}^{3}$ were collected in RNAprotect Tissue Reagent (Qiagen Benelux, Venlo, The Netherlands) and stored at $-80^{\circ} \mathrm{C}$.

\subsection{Western Blot}

Frozen liver tissue samples were homogenized in a radio-immunoprecipitation assay buffer containing $1 \%(w / v)$ protease and phosphatase inhibitor cocktail, and $1 \%(w / v)$ EDTA 0.5 M (all from Thermo Scientific, Merelbeke, Belgium). Samples were sonicated for $30 \mathrm{~s}$, rotated for $15 \mathrm{~min}$ at $4{ }^{\circ} \mathrm{C}$, centrifuged for $5 \mathrm{~min}$ at $14,000 \times g$ and the supernatants were transferred into $2 \mathrm{~mL}$ microtubes (VWR, Leuven, Belgium). Protein quantification was performed on the supernatants using the Pierce ${ }^{\mathrm{TM}}$ bicinchoninic acid protein assay (Thermo Scientific) with bovine serum albumin (BSA) as reference standard. Both proteins (Fah and Hpd) were separated by electrophoresis on $12 \%(w / v)$ Mini-Protein ${ }^{\circledR}$ TGX StainFree $^{\mathrm{TM}}$ precast gels (Bio-Rad, Temse, Belgium) and blotted onto nitrocellulose Trans-Blot ${ }^{\circledR}$ Turbo $^{\mathrm{TM}}$ Transfer packs (Bio-Rad). Membranes were blocked in blocking buffer consisting $5 \%(v / v)$ non-fatty milk in Tris-buffered saline solution $(20 \mathrm{mM}$ Tris and $135 \mathrm{mM}$ sodium chloride) and $0.1 \%(v / v)$ Tween-20, followed by incubation overnight at $4{ }^{\circ} \mathrm{C}$ with primary antibody (both diluted 1:1000 in blocking buffer) directed against Fah (HPA041370) and Hpd (HPA038322) and several wash steps in Tris-buffered saline solution containing $0.1 \%$ $(v / v)$ Tween-20 to remove excessive antibody (all from Sigma-Aldrich). Subsequently, membranes were incubated for $1 \mathrm{~h}$ at room temperature with polyclonal goat anti-rabbit secondary antibody (Dako, Agilent Technologies, Heverlee, Belgium) diluted 1:1000 in blocking buffer and washed again several times. Detection of the proteins was carried out by means of a Pierce ${ }^{\mathrm{TM}}$ enhanced chemiluminescence Western blotting substrate kit (Thermo Scientific) according to the manufacturer's instructions. Chemiluminescent detection of both target proteins was done on a ChemiDoc ${ }^{\mathrm{TM}} \mathrm{MP}$ Imaging System and analyzed using Image Lab 5.0 software (all from Bio-Rad, Temse, Belgium).

\subsection{Isolation of RNA and Reverse Transcriptase-Polymerase Chain Reaction (PCR)}

Total RNA was extracted from all samples using the GenElute Mammalian Total RNA Purification Miniprep Kit (Sigma-Aldrich) according to the manufacturer's instructions. The isolated RNA was quantified at $260 \mathrm{~nm}$ using a Nanodrop spectrophotometer (Thermo Scientific, Merelbeke, Belgium). Total RNA was reverse transcribed into cDNA using iScript $^{\mathrm{TM}}$ cDNA Synthesis Kit (Bio-Rad) followed by cDNA purification with the Genelute PCR clean up kit (Sigma-Aldrich).

\subsection{Quantitative Real-Time PCR ( $q P C R$ )}

A StepOne Plus system (Thermo Scientific) was used for RT-qPCR using TaqMan fast advanced master mix and gene expression assays (see Table S1). Data normalization was done against the mean of the reference genes glyceraldehyde-3-phosphate dehydrogenase (Gapdh), hydroxymethylbilane synthase (Hmbs) and ubiquitin C (Ubc) using qbase+ software (Biogazelle, Zwijnaarde, Belgium). 


\subsection{Dried Blood SPOT (DBS) Analysis}

Used reagents and solvents (methanol, acetonitrile and formic acid) of the purest available quality (gradient HPLC) were supplied by Merck. AB Sciex API 3200 and API 4000 (both MS analyzers), coupled to an HPLC 1100 Agilent system were used for analysis. For the quantification of the amino acids tyrosine $(\mathrm{m} / \mathrm{z} 238>102)$ and phenylalanine $(\mathrm{m} / \mathrm{z}$ $222>102$ ), discs of $3.2 \mathrm{~mm}$ diameter were punched, using a DBS Puncher (Perkin Elmer, Mechelen, Belgium), and placed into a 96-wellplate. Internal standards were added in separate wells and DBS were eluted for $20 \mathrm{~min}$ at room temperature using $200 \mu \mathrm{L}$ methanol. $40 \mu \mathrm{L}$ of the eluent was transferred into a second 96-wellplate, while the residues of the first plate were dried and stored for SA sampling (see hereafter). To each well of the second plate, $160 \mu \mathrm{L}$ stock solution containing labeled amino acids standards (Cambridge Isotopes Labeled Amino Acid Standards NSK-A) was added. The plate was dried at $55{ }^{\circ} \mathrm{C}$ under nitrogen atmosphere for $15 \mathrm{~min}$, reconstituted in $25 \mu \mathrm{L}$ Butanol- $\mathrm{HCl}$ mixture (SigmaAldrich) and incubated for $20 \mathrm{~min}$ at $65^{\circ} \mathrm{C}$ under inert atmosphere. After final evaporation under a flow of nitrogen, $200 \mu \mathrm{L}$ of eluting solution (acetonitrile-water-formic acid mixture (80:20:0.5)) was added. The samples were analyzed by MS/MS through direct flow injection using the same eluting solution. Final concentrations were obtained using labeled internal standards $\left({ }^{13} \mathrm{C}_{6}\right.$ Phenylalanine, $m / z 228>102$ and ${ }^{13} \mathrm{C}_{6}$ Tyrosine, $\left.m / z 244>102\right)$. For SAquantification $(m / z 211>137)$, the aforementioned dried samples (plate 1) were for $40 \mathrm{~min}$ at $50{ }^{\circ} \mathrm{C}$ derivatized by $200 \mu \mathrm{L}$ hydrazine hydrate solution (acetonitrile-water-formic acidhydrazine mixture (80:20:0.5:0.5) with deuterated SA as internal standard $(m / z 216>142)$ ). Samples were transferred to a new 96-wellplate to discard punches and subsequentially analyzed by MS/MS through direct flow injection. Final concentrations were obtained using a standard curve. For NTBC measurements $(m / z 330>218$ and $330>126)$, discs of $3.2 \mathrm{~mm}$ diameter were punched using a cutting tool (Sigma-Aldrich) and placed into $1.5 \mathrm{~mL}$ Eppendorf tubes. Punches were eluted for $30 \mathrm{~min}$ at room temperature using $200 \mu \mathrm{L}$ of pure methanol and $1 \mu \mathrm{M}$ of internal standard $\left({ }^{13} \mathrm{C}_{6}\right.$ nitisinone, $\mathrm{m} / \mathrm{z} 336>218$ and $336>$ 126). After discarding the punch, solutions were directly used in LC/MS. $10 \mu \mathrm{L}$ of sample solution was eluted by a Poroshell 120 EC-C18 column (Agilent) using a isocratic method $(0.5 \mathrm{~mL} / \mathrm{min}$ acetonitrile-water mixture $(85: 15)$ with $0.05 \%$ formic acid $)$ at $30{ }^{\circ} \mathrm{C}$. Final concentrations were obtained using a standard curve.

\subsection{Histopathology}

Paraffin-embedded liver tissue was deparaffinized using xylene (VWR) and decreasing concentrations of ethanol (VWR). Next, a nuclear counterstaining was performed using Mayer's hematoxylin (Sigma-Aldrich). Subsequently, samples were dehydrated using increasing concentrations of ethanol and xylene and mounted with acrytol (Leica, Diegem, Belgium).

\subsection{Microarray Profiling}

Total RNA (100 ng) was used for amplification and in vitro transcription using the Genechip 3' IVT Express Kit following the manufacturer's instructions. The amplified RNA (aRNA) was purified with magnetic beads and $15 \mu \mathrm{g}$ Biotin-aRNA was treated with fragmentation reagent. $12.5 \mu \mathrm{g}$ fragmented aRNA was hybridized to Affymetrix Mouse 4302.0 arrays along with a hybridization cocktail solution and then placed in a Genechip ${ }^{\circledR}$ Hybridization Oven- 645 rotating at $60 \mathrm{rpm}$ at $45^{\circ} \mathrm{C}$ for $16 \mathrm{~h}$. After incubation, arrays were washed on a Genechip ${ }^{\circledR}$ Fluidics Station 450 and stained with the Affymetrix HWS kit as indicated by the manufacturer's protocols. The chips were scanned with an Affymetrix GeneChip ${ }^{\circledR}$ Scanner $30007 \mathrm{G}$ and the quality control matrices were confirmed with the Affymetrix GCOS software following the manufacturer's guidelines. Background correction, summarization (median polish) and normalization (quantile) were done with Robust Multiarray Analysis (all from Affymetrix, Merelbeke, Belgium). The data discussed in this publication have been deposited in the NCBI Gene Expression Omnibus and is accessible through GEO Series accession number GSE161478. Heatmaps and volcano plots 
were generated using the Transcriptome Analysis Console (TAC) version 4.0 (Thermo Scientific). Ingenuity Pathway Analysis software (version 2020) was used for gene set enrichment and pathway analyses considering only genes with a $\geq 5$-fold difference in expression and False Discovery Rate (FDR) $p$-value $\leq 0.05$.

\section{Results}

\subsection{Short-Term NTBC Therapy Discontinuation Inflicts Severe Liver Damage in Fah-Deficient Mice}

To study the impact of short-term NTBC therapy discontinuation in HT1 patients, FRG mice deficient in Fah were used as surrogate model. Hence, in a first set of experiments, we confirmed the knockout of Fah in FRG mouse livers by western blot analysis (Figure 2A) as well as the constitutive expression of $\mathrm{Hpd}$, the therapeutic target of NTBC, in these livers (Figure 2B). Wildtype (WT) C57Bl/6 mice were used as positive controls (Figure 2A,B).
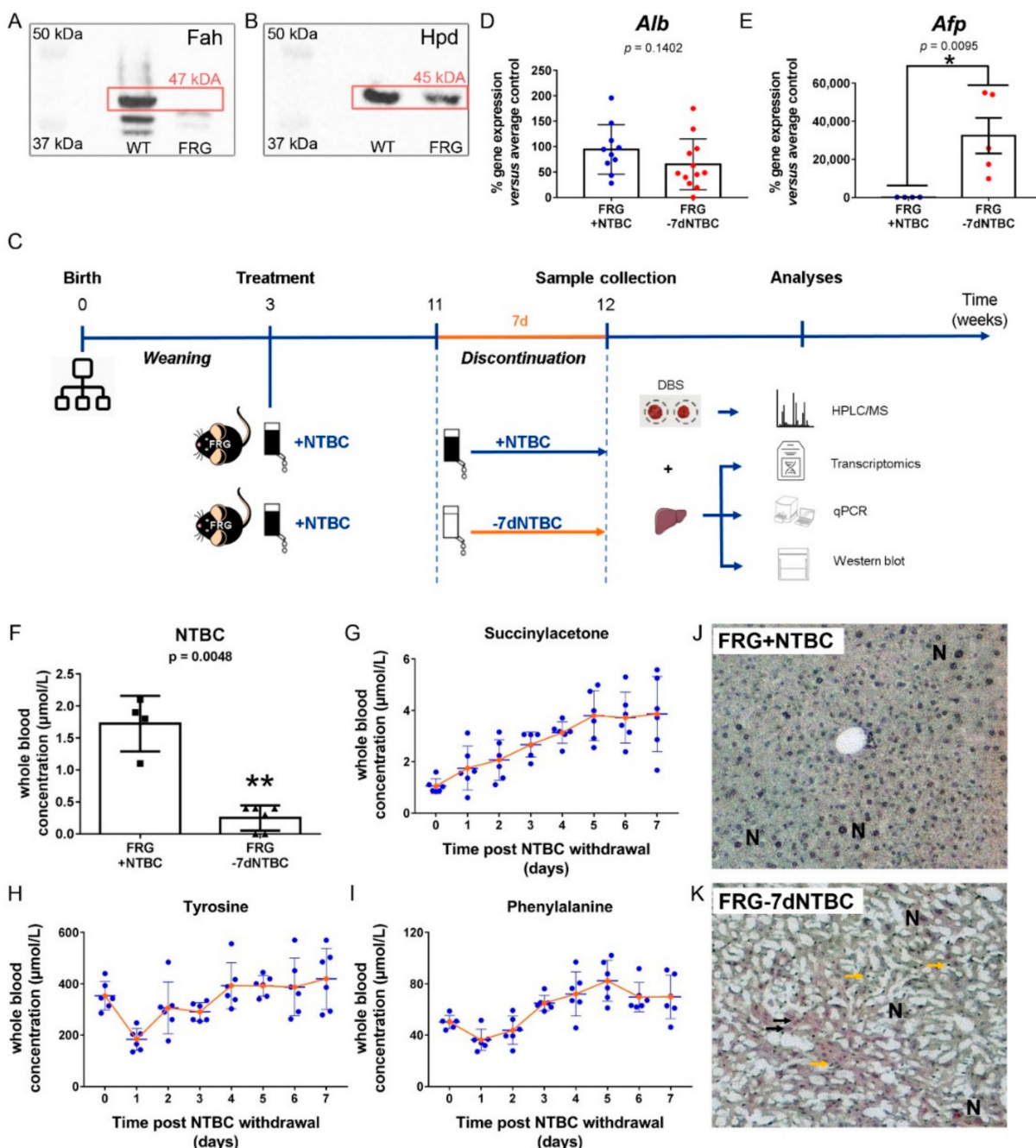

Figure 2. Molecular and biochemical evaluation of the FRG mouse model. FRG mouse livers are characterized by (A) the absence of Fah and (B) the presence of Hpd protein expression using western blot with healthy wildtype (WT) C57Bl/6 mice as positive controls. (C) Schematic representation of the NTBC drug therapy discontinuation experiment in FRG mice and subsequent sample collection. (D,E) Gene expression analysis of mouse albumin $(A l b)$ and alpha-fetoprotein $(A f p)$ by RT-qPCR. (F) Quantification of NTBC blood levels and daily follow up of (G) succinylacetone, (H) L-tyrosine and (I) L-phenylalanine levels using LC-MS/MS analyses of dried blood spots (DBS). Histopathological analysis of FRG mouse livers under $(\mathrm{J})$ continuous NTBC therapy and $(\mathbf{K})$ seven days post NTBC withdrawal by hematoxylin staining showing large dysmorphic nuclei (N), oval-like cells (black arrow) and small lymphoid cells (yellow arrow). * significantly increased; ** significantly decreased using a two-tailed Mann-Whitney test $(p<0.05)$. 
Next, NTBC therapy of FRG mice was discontinued for seven consecutive days (FRG$7 \mathrm{dNTBC}$ ) or continuously administered (FRG+NTBC) as shown in Figure 2C. We found that albumin $(A l b)$ expression was slightly, but not significantly, decreased whereas alphafetoprotein $(A f p)$ was significantly increased (245-fold) in Fah-deficient mouse livers after short-term NTBC discontinuation $(65.14 \pm 50.17 \%)$ versus continuous NTBC administration (94.34 $\pm 48.91 \%$ ) (Figure 2D,E). Quantification of NTBC blood levels in FRG mice at seven days post withdrawal confirmed the drug therapy discontinuation $(0.25 \pm 0.08 \mu \mathrm{M})$ versus FRG mice under continuous NTBC treatment $(1.73 \pm 0.22 \mu \mathrm{M})$ (Figure 2F). Furthermore, daily follow up of HT1 blood parameters showed that SA levels raised steadily whereas tyrosine and phenylalanine levels remained quite stable after NTBC therapy withdrawal (Figure 2G-I). Finally, histopathological investigations confirmed the presence of severe liver lesions in NTBC-deprived FRG mice as opposed to FRG mice under continuous NTBC therapy (Figure 2J,K). More specifically, FRG mice continuously treated with NTBC only presented mild hepatocellular changes as hepatocytes were enlarged and regularly showed large dysmorphic nuclei (N) with several well-formed nucleoli (Figure 2J; Figure S1). In strong contrast, FRG mice at seven days post withdrawal of NTBC presented severe hepatocellular changes including necrosis of hepatocytes, enlarged hepatocytes, large dysmorphic nuclei $(\mathrm{N})$, oval-like cells (black arrow), and infiltration of small lymphoid cells with dark nuclei and scant cytoplasm (yellow arrow) (Figure 2K; Figure S1).

\subsection{Glutathione Metabolism and Oxidative Stress Related Pathways Are Activated in Fah-Deficient Livers upon Short-Term NTBC Therapy Discontinuation}

Total RNA, extracted from liver tissue of FRG+NTBC and FRG-7dNTBC mice, was subjected to whole transcriptome profiling using Affymetrix Mouse 4302.0 arrays and Ingenuity Pathway Analysis software. We found that seven days after NTBC therapy discontinuation, $4.65 \%$ (2096 genes) of the expressed genes was more than 2-fold and $0.72 \%$ (324 genes) even more than 5-fold up regulated, whereas 3.45\% (1555 genes) of the expressed genes was significantly down regulated for more than 2 -fold and $0.60 \%$ (271 genes) was even more than 5-fold decreased (Figure 3A,B; Table S2).

When considering only genes that were at least 5-fold up or down regulated after short-term NTBC therapy discontinuation, we found that these genes grouped together in toxicological gene classes related to liver disease (Fibrosis of liver, Progressive familial intrahepatic cholestasis type 1, Intrahepatic cholestasis, Hepatic steatosis, Cholestasis), liver damage (Hepatic injury, Apoptosis of liver cells, Liver damage, Cell death of hepatocytes, Cell death of liver cells, Necrosis of liver), liver regeneration (Proliferation of liver cells, Liver regeneration) and liver cancer (Metastatic liver tumor, Hepatocellular carcinoma) of which Hepatocellular carcinoma was the most pronounced toxicological gene class harboring 62 significantly modulated genes including alpha-fetoprotein ( $A f p$ ) that was 24-fold increased (Figure 3C,D; Table S2). Furthermore, upstream regulator analyses support these findings (Table S3). More specifically, in the context of liver damage and regeneration, we found that the hepatogenic growth factors epidermal growth factor $(E g f)$ and hepatocyte growth factor $(\mathrm{Hgf})$ were predicted to be active as well as the pro-fibrotic transforming growth factor beta 1 (Tgfb1) (activation z-score $\geq 2$; Table S3). 
A

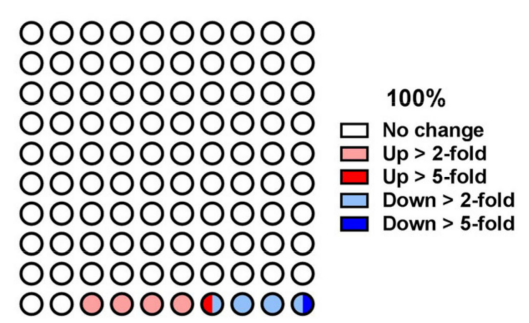

B

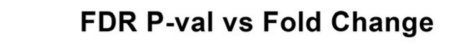

C

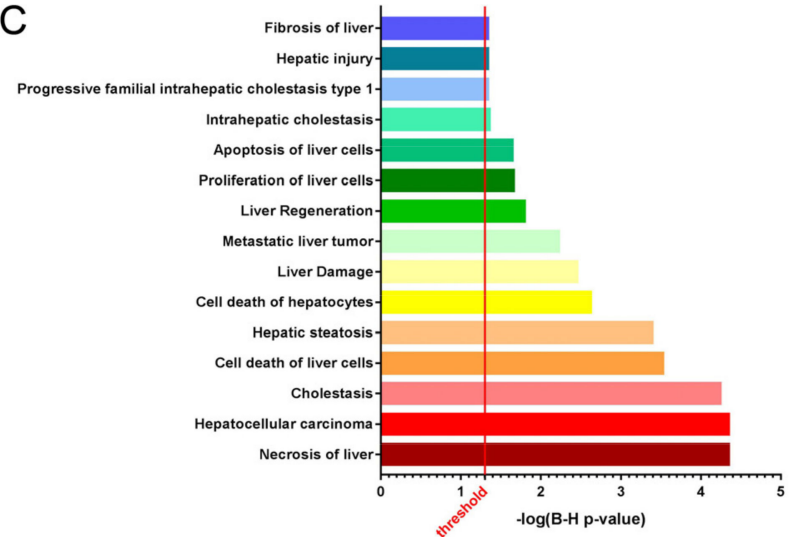

D

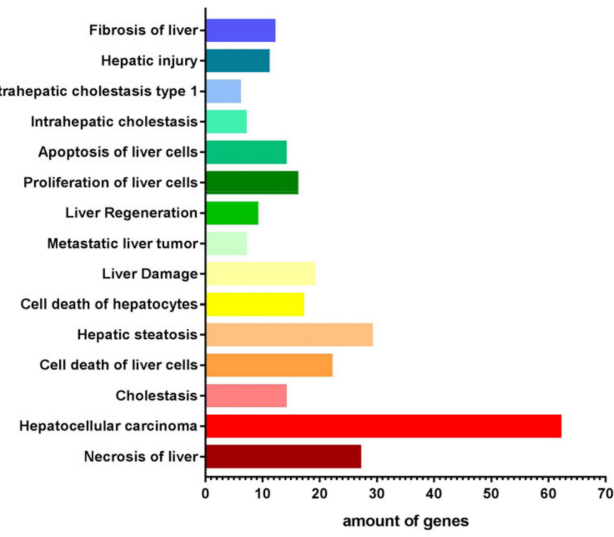

F
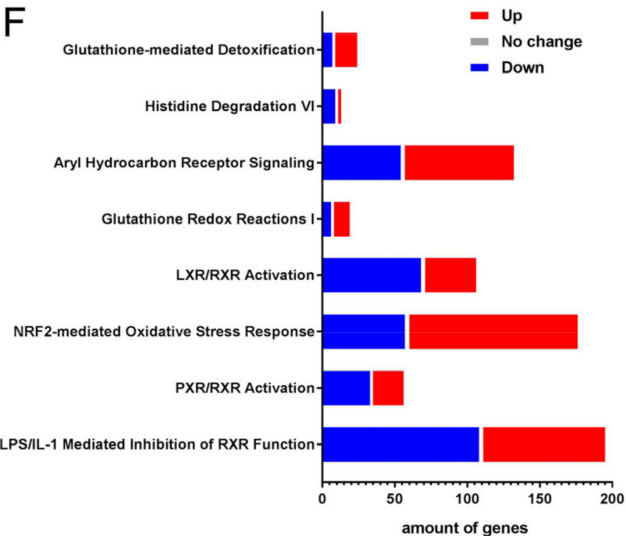

Figure 3. Whole transcriptome analyses of FRG liver tissue after seven days of NTBC therapy discontinuation versus continuous treatment. (A) Percentage of modulated genes in liver tissue. (B) Volcano plot displaying 5-fold up and down regulated genes with FDR $p$-value $\leq 0.05$. (C,D) Toxicological gene class grouping of 5 -fold up and down regulated genes showing the Benjamini-Hochberg $(\mathrm{B}-\mathrm{H}) p$-value of overlap and amount of modulated genes. (E,F) Canonical pathway analyses showing B-H $p$-value of overlap, activation z-scores and amount of modulated genes.

Canonical pathway analyses showed that pathways related to glutathione metabolism (Glutathione-mediated detoxification, Glutathione redox reactions $I$ ) as well as oxidative stress response (NRF2-mediated oxidative stress response) were activated in the liver seven days after NTBC therapy withdrawal (Figure 3E). In contrast, the Aryl hydrocarbon receptor signaling and $L X R / R X R$ activation pathways were found to be inhibited (Figure 3E). With respect to the NRF2-mediated oxidative stress response pathway, 118 genes were found to be at least 5 -fold up regulated, whereas 58 genes were found to be at least 5-fold down regulated (Figure 3F). More specifically, Abcc4 (11-fold), Cbr1 (7-fold), Gsta1 (8-fold), Gpx2 (13-fold), Gsr (13-fold), Hacd3 (8-fold), Hmox1 (59-fold), Hspb8 (6-fold), Mgst2 (40-fold), Mgst3 (23- 
fold), Nqo1 (15-fold), and Txnrd1 (5-fold) were found to be among the top increased genes after short-term NTBC therapy discontinuation related to the NRF2-mediated oxidative stress response (Figure $4 \mathrm{C}$ ). In addition, several gene classes related to reactive oxygen species (ROS) metabolism were found to be significantly modulated (Figure $4 \mathrm{~A}, \mathrm{~B})$. As such, we found that the ROS-related genes Adm, Bcl2l11, Cdkn1a, Cyp1a1, G6pd2, G6pdx, Ggt1, Gmfb, Gsr, Hmox1, Lcn2, Maoa, Mt2, Nqo1, Pgd, Pon3, Ptgs2, Slc7a11, and Ucp2 were at least 5-fold up regulated whereas the genes Car3, Egfr, Nox4, Prodh, and Tert were at least 5-fold down regulated (Figure 4D). Out of these ROS-related genes the top increased genes were Slc7a11 (300-fold) and Ggt1 (121-fold) (Figure 4D,F,G).

A

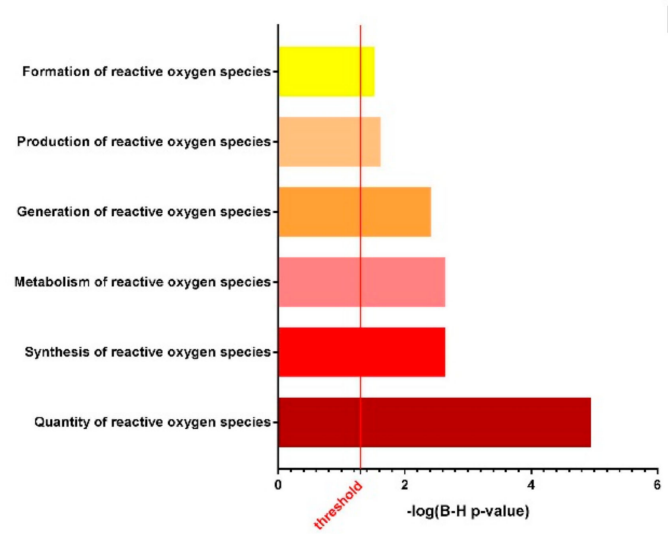

C

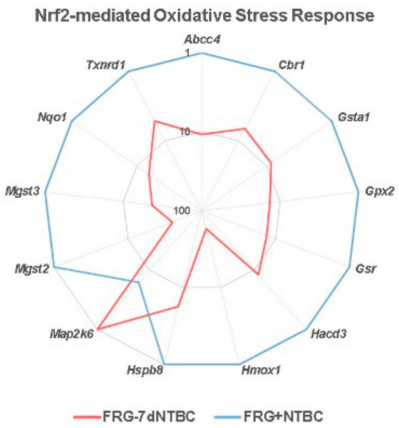

B

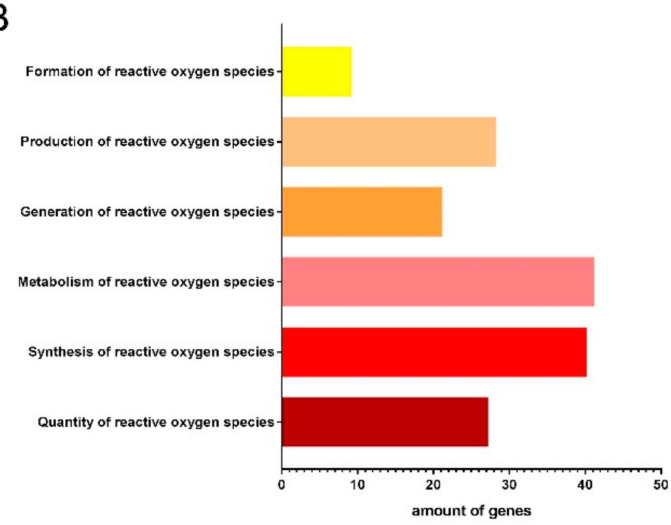

D

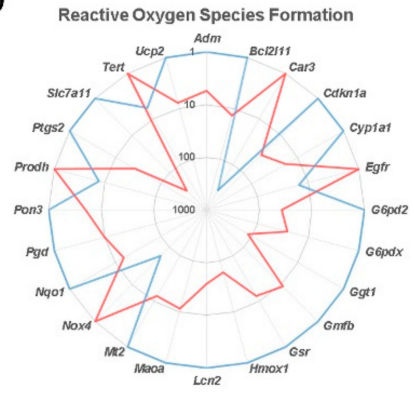

$E$

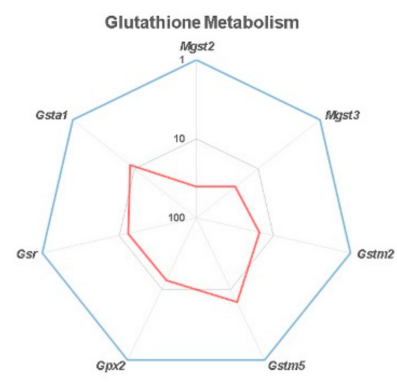

-FRG-7dNTBC -FRG+NTBC
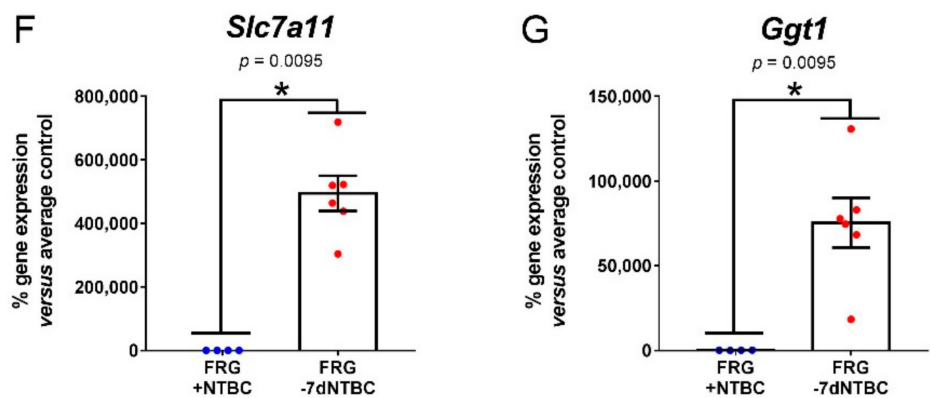

Figure 4. NTBC therapy discontinuation activates oxidative stress responses, reactive oxygen species (ROS) formation and glutathione metabolism. (A,B) ROS-related gene class grouping of 5-fold up and down regulated genes showing B-H $p$-value of overlap and amount of modulated genes. Spider graphs showing differentially-expressed genes related to (C) Nrf2-mediated oxidative stress response, (D) reactive oxygen species formation, and (E) glutathione metabolism. $(\mathbf{F}, \mathbf{G})$ Gene expression analysis of top increased ROS-related genes by RT-qPCR. * significantly increased using a two-tailed Mann-Whitney test $(p<0.05)$.

In the context of glutathione metabolism, respectively 13 genes were at least 5 -fold up and 7 genes down regulated in the Glutathione redox reactions I pathway whereas for the Glutathione-mediated detoxification pathway 17 genes were at least 5-fold up regulated 
and 8 genes at least 5 -fold down regulated (Figure 3F). Moreover, the expression of the following glutathione metabolism related genes Mgst2 (40-fold), Mgst3 (23-fold), Gstm2 (15-fold), Gstm5 (7-fold), Gpx2 (13-fold), Gsr (13-fold), and Gsta1 (8-fold) was found to be highly increased after short-term NTBC therapy deprivation (Figure 4E).

\subsection{Fah-Deficient Liver Tissue Exhibits Increased Expression of Liver Progenitor Markers after} Short-Term NTBC Therapy Discontinuation

Liver regeneration was one of the major toxicological gene classes that was found to be significantly modulated in Fah-deficient mouse livers when NTBC therapy was discontinued (Figure 3C,D). Therefore, we investigated the gene expression of a large set of quiescent and activated liver progenitor cell (LPC) and biliary epithelial cell (BEC) markers. These LPCs and BECs are endogenous cells that are known to differentiate into hepatocytes and cholangiocytes, and frequently accompany chronic liver diseases (Figure 5A) [30]. In this context, we found that the gene expression of the LPC/BEC markers Atf3 (19-fold), Cyr61 (7-fold), Ddr1 (6-fold), Elovl7 (38-fold), Glis3 (8-fold), and Hspa1a (6-fold) was significantly increased more than 5-fold in Fah-deficient livers when NTBC therapy was discontinued for seven consecutive days using microarray analyses (Figure 5A,B).

A
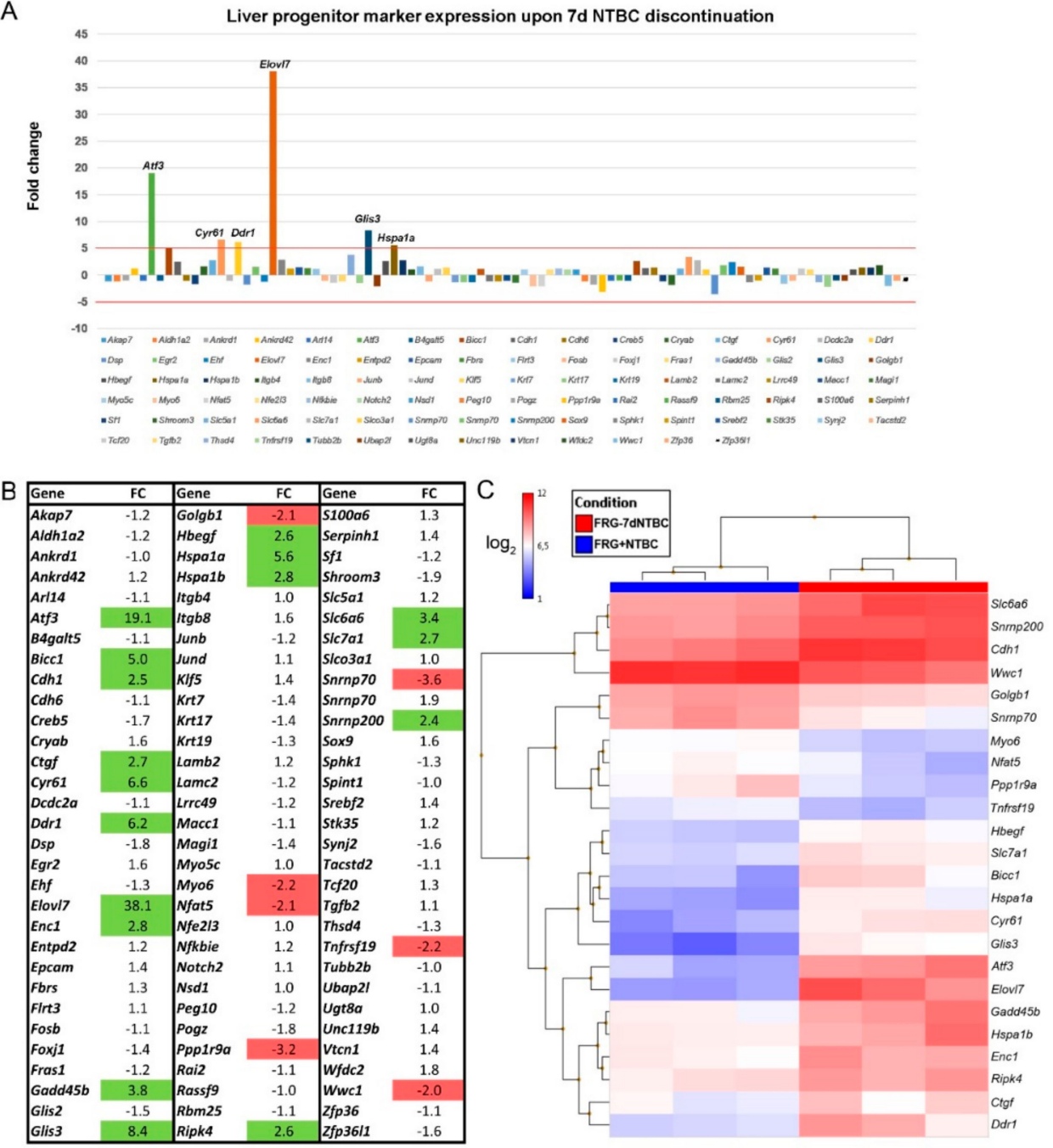

Figure 5. Liver progenitor cell (LPC)/biliary epithelial cell (BEC) marker expression in Fah-deficient mouse livers after short-term NTBC therapy discontinuation. (A,B) Gene expression profiling of LPC/BEC markers using microarray analyses. (C) Hierarchical clustering of differentially-expressed LPC/BEC markers. 
Hierarchical clustering using differentially-expressed LPC/BEC markers allowed to discriminate between liver tissue of Fah-deficient mice under continuous NTBC therapy and after seven days of NTBC therapy withdrawal (Figure 5C). Furthermore, RT-qPCR analyses of commonly used LPC/BEC markers confirmed that Atf3 (83-fold), Cyr61 (5.5fold), Ddr1 (12-fold), Elovl7 (266-fold), and Glis3 (13-fold) gene expression was significantly increased and showed that Epcam expression was increased approximately 4-fold in Fahdeficient livers when NTBC therapy has been discontinued (Figure 6). In contrast, the observed increase in Hspa1a expression could not be confirmed using RT-qPCR and no significant difference in gene expression was observed for other commonly used LPC markers Cd24a, Krt19, and Prom1 (Figure 6).
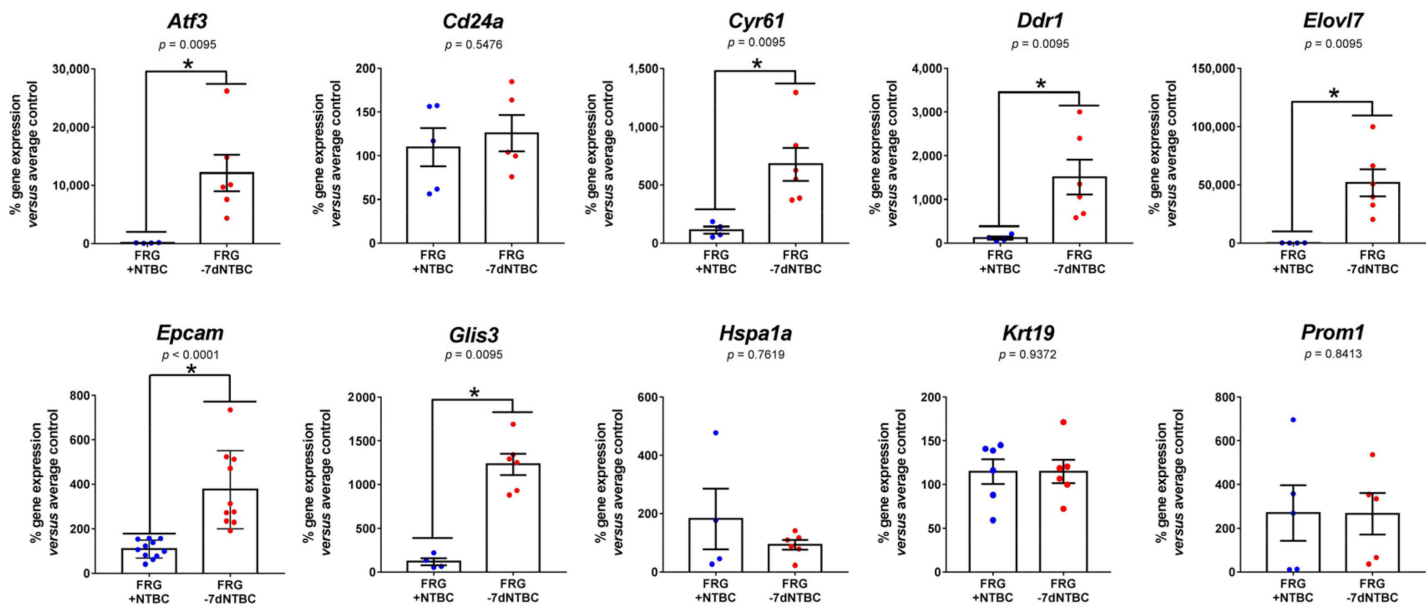

Figure 6. Gene expression analysis of LPC/BEC identification markers by RT-qPCR. * significantly increased using a two-tailed Mann-Whitney test $(p<0.05)$.

\section{Discussion}

Since its introduction, NTBC therapy has clearly improved the vital prognosis and the quality of life of HT1 patients. However, due to its strict drug and associated dietary regime, compliance problems have been described [31-33]. More specifically, it has been reported that HT1 patients have presented with recurrent porphyria-like neurological crises after discontinuation/interruption of NTBC treatment. For some of the patients, these crises were life-threatening and accompanied by respiratory muscle paralysis requiring ventilator support, hemodynamic disturbance, acute progressive ascending motor neuropathy causing profound impairment, recurrent seizures, and neuropathic pain [10]. To gain insight on the molecular impact of non-drug compliance by HT1 patients, we compared transcriptome profiles of liver tissue of Fah-deficient mice under continuous NTBC therapy and after short-term, i.e., seven days NTBC therapy discontinuation.

Biochemical blood analyses of Fah-deficient mice after NTBC withdrawal showed increased SA levels, indicating that the inhibitory effects of the drug NTBC became inefficient seven days after the last dose which was associated with liver damage. SA can also be considered as an indirect indicator of redox imbalance as it has been shown that treatment of rodents with SA methyl ester leads to 5-aminolevulinic acid (ALA) accumulation that has been associated with induced oxidative subcellular and tissue damage within the liver [34]. This is in accordance with previous findings in similar HT1 mouse models showing that the half-life of NTBC in mouse plasma was $54 \mathrm{~h}$. Hpd is therefore only completely inhibited during the first three days following a single-dose of NTBC and fully regains its enzymatic activity seven days after NTBC therapy discontinuation [35]. Furthermore, transcriptome analyses of liver tissue revealed that molecular pathways associated with oxidative stress, glutathione metabolism and liver regeneration become activated in HT1 mice upon short-term NTBC therapy discontinuation. 
With respect to genes involved in oxidative stress, ROS formation and glutathione metabolism, Ggt1 (121-fold) and Slc7a11 (300-fold) expression was mostly increased. Ggt1 encodes an enzyme that catalyzes the transfer of the glutamyl moiety of glutathione (GSH) to a variety of amino acids and dipeptide acceptors. The observed highly increased gene expression of Ggt1 in Fah-deficient liver tissue after short-term NTBC deprivation is in accordance with high gamma glutamyl transferase activity levels observed in untreated HT1 patients [36]. Slc7a11 encodes the cystine/glutamate antiporter (xCT) and imports cystine as a precursor for GSH synthesis that supports antioxidant responses [37]. This massive increase in $\mathrm{Slc7a11}$ expression indicates that GSH depletion is already present seven days post NTBC withdrawal. This might be explained by the accumulation of the powerful GSH depletor fumarylacetoacetate, which triggers secondary mechanisms such as $\mathrm{xCT}$ to compensate for the shortage of GSH [9]. Recently, it was also reported that Slc7a11 is a key player in liver regeneration as its overexpression in hepatocytes enhances, and its suppression inhibits, liver repopulation following toxic injury [38]. Therefore, the increased expression of Slc7a11 cannot only be considered as an indication that GSH metabolism becomes activated in the liver after short-term NTBC therapy discontinuation to counteract ROS formation. It also suggests that liver regeneration processes have started [38].

To support this, we compared the LPC / BEC marker expression profile of liver tissue derived from NTBC-treated Fah-deficient mice and those that were deprived from NTBC for seven days. This gene expression profile was previously established using meta-analyses of human and mouse biliary epithelial cell gene profiles [30] and allowed us to discriminate between the two experimental groups. More specifically, we found that the gene expression of several LPC/BEC markers including Atf3, Cyr61, Ddr1, Elovl7, Epcam, Glis3, and Hspa1a was highly increased in Fah-deficient livers when NTBC therapy was discontinued for seven consecutive days. This data could be confirmed by RT-qPCR analyses for all markers except Hspa1a.

Atf3, also known as liver regeneration factor 1, belongs to the basic leucine zipper family of transcription factors [39]. It is an early response gene that is rapidly induced upon partial hepatectomy and induced in hepatocyte cultures stimulated with mitogenic growth factors [39,40]. A large number of studies have shown that Atf 3 is a stress-inducible gene [41], but may also prevent apoptosis [42], stimulate cell proliferation [43], and tumor invasion [44].

Cyr61 encodes a matricellular protein that is involved in dampening and resolving liver fibrosis, mediates cholangiocyte proliferation and the ductular reaction. Both are repair responses to cholestatic injury of the liver [45].

$D d r 1$ belongs to a unique family of receptor tyrosine kinases containing a discoidin homology domain in their extracellular region. DDRs are expressed during early embryonic development in different tissues of which $D d r 1$ is mainly expressed in epithelia [46]. Interestingly, $D d r 1$ expression has been reported in hepatocytes and bile duct epithelial cells of cirrhotic liver, but its role remains largely unclear [47].

Elovl7 encodes a key enzyme involved in the elongation of very long chain fatty acids and has been shown to be up regulated upon hepatocyte dedifferentiation [48].

Epcam is a surface epithelial marker that is selectively expressed in the biliary tree, where it discriminates liver progenitor cells from mature cholangiocytes [49]. In addition, mature hepatocytes within the hepatic parenchyma also do not express Epcam [49]. Moreover, it is a commonly used marker to isolate LPCs from liver disease samples [50]. Furthermore, it was previously reported that Epcam ${ }^{+} / \mathrm{Afp}^{+}$hepatocellular carcinoma subtypes exhibit features of hepatic stem/progenitor cells and display hepatic cancer stem cell-like traits including the abilities to self-renew and differentiate [51]. Therefore, our observed increased Epcam and Afp expression indicates that short-term NTBC therapy discontinuation might already be sufficient to put HT1 patients back at risk of developing hepatocellular carcinoma.

Glis3 is a transcription factor containing a five Kruppel-like zinc finger motif. Its expression occurs early in embryogenesis and is thought to play a critical role in the cellular 
regulation of development by functioning as a repressor or activator of transcription. Mutations in the Glis3 gene have led to neonatal diabetes, thyroid and renal diseases, and liver dysfunction ranging from hepatitis to cirrhosis [52].

Hspa1a, also known as Hsp70, has been shown to function as a chaperone during periods of cellular stress and induces the expression of several inflammatory cytokines identified as key players during early liver regeneration. Indeed, previous studies in mice have shown that the early phase of successful liver regeneration requires the presence of Hspa1a [53].

The massive up regulation of these LPC/BEC markers correlates with our histopathological observation of hepatocyte loss and oval-like cell proliferation and supports the predicted activation of liver repair mechanisms by our transcriptomics-based pathway analyses.

\section{Conclusions}

This study provides new data on the alteration of the HT1 liver transcriptome when NTBC therapy is withdrawn for a short period. We successfully identified a number of genes related to oxidative stress responses, glutathione metabolism and liver regeneration that were highly differentially-expressed versus continuous NTBC treatment. Especially in the context of liver regeneration we found a highly increased expression of a number of LPC/BEC markers when NTBC therapy was discontinued of which some, including Epcam, could also play a key role in hepatocellular carcinoma development associated with HT1 disease progression. However, to fully understand the pathophysiological impact of the experimentally observed transcriptional activation of oxidative stress, glutathione metabolism, and liver regeneration pathways upon short-term NTBC therapy discontinuation, combining these transcriptional data with subsequent integrative metabolomics studies will be of key importance [54,55]. High resolution metabolite profiling of, e.g., blood, urine, or cerebrospinal fluid will allow to study the direct and indirect consequences of the observed transcriptional changes in HT1 liver tissue at a biochemical level by identifying and measuring thousands of chemical features. In addition, experiments on HT1 patient-derived liver cells in vitro and in vivo in immune deficient mice after xenografting, will allow to further extrapolate our new findings from preclinical mouse studies to the situation in man [56].

Supplementary Materials: The following are available online at https:/ / www.mdpi.com/2073-442 5/12/1/3/s1, Figure S1: Histopathology confirms presence of severe liver lesions in NTBC-deprived FRG mice, Table S1: Taqman gene expression assays, Table S2: Differential gene expression in liver tissue of FRG-7dNTBC versus FRG+NTBC mice with 5-fold cut-off and FDR $p$-value $\leq 0.05$, Table S3: Upstream regulator prediction in FRG-7dNTBC versus FRG+NTBC liver tissue.

Author Contributions: Conceptualization, H.C.-V., J.D.K., and G.A.M.; Investigation, H.C.-V., J.N., J.D.K., G.A.M., L.M.; Methodology, H.C.-V., J.N., P.C., S.B., G.A.M., and L.M.; Resources, T.V., L.M., G.C., P.G., J.D.K., and G.A.M.; Data Curation, H.C.-V., L.M., and J.D.K.; Writing-Original Draft Preparation, H.C.-V., J.D.K.; Writing—Review and Editing, H.C.-V., J.N., J.D.K., L.M., P.C., S.B., G.A.M., T.V., G.C., and P.G.; Visualization, H.C.-V., J.D.K.; Supervision, T.V., G.A.M., and J.D.K.; Funding Acquisition, T.V., G.A.M., and J.D.K. All authors have read and agreed to the published version of the manuscript.

Funding: This research was funded by the Research Foundation-Flanders (FWO) grant numbers $1139117 \mathrm{~N}$ and 1518619N, the Research Council (OZR) of the Vrije Universiteit Brussel (VUB), the Hercules Foundation grant number HERC26 and Wetenschappelijk Fonds Willy Gepts (WFWG) from the UZ Brussel. The APC was funded by the Vrije Universiteit Brussel.

Conflicts of Interest: The authors declare that they have no conflict of interest. 


\section{References}

1. De Laet, C.; Dionisi-Vici, C.; Leonard, J.V.; McKiernan, P.; Mitchell, G.; Monti, L.; de Baulny, H.O.; Pintos-Morell, G.; Spiekerkötter, U. Recommendations for the management of tyrosinaemia type 1. Orphanet J. Rare Dis. 2013, 8, 8. [CrossRef]

2. Alvarez, F.; Atkinson, S.; Bouchard, M.; Brunel-Guitton, C.; Buhas, D.; Bussières, J.F.; Dubois, J.; Fenyves, D.; Goodyer, P.; Gosselin, M.; et al. The Québec NTBC study. Adv. Exp. Med. Biol. 2017, 959, 187-195. [PubMed]

3. Larochelle, J. Discovery of hereditary tyrosinemia in Saguenay-Lac St-Jean. Adv. Exp. Med. Biol. 2017, 959, 3-8.

4. Äärelä, L.; Hiltunen, P.; Soini, T.; Vuorela, N.; Huhtala, H.; Nevalainen, P.I.; Heikinheimo, M.; Kivelä, L.; Kurppa, K. Type 1 tyrosinemia in Finland: A nationwide study. Orphanet J. Rare Dis. 2020, 15, 1-11. [CrossRef] [PubMed]

5. Bliksrud, Y.T.; Brodtkorb, E.; Backe, P.H.; Woldseth, B.; Rootwelt, H. Hereditary tyrosinaemia type 1 in Norway: Incidence and three novel small deletions in the fumarylacetoacetase gene. Scand. J. Clin. Lab. Invest. 2012, 72, 369-373. [CrossRef] [PubMed]

6. Mitchell, G.A.; Yang, H. Remaining challenges in the treatment of tyrosinemia from the clinician's viewpoint. Adv. Exp. Med. Biol. 2017, 959, 205-213.

7. Phaneuf, D.; Labelle, Y.; Berube, D.; Arden, K.; Cavenee, W.; Gagne, R.; Tanguay, R.M. Cloning and expression of the cDNA encoding human fumarylacetoacetate hydrolase, the enzyme deficient in hereditary tyrosinemia: Assignment of the gene to chromosome 15. Am. J. Hum. Genet. 1991, 48, 525-535.

8. Maiorana, A.; Dionisi-Vici, C. NTBC and correction of renal dysfunction. Adv. Exp. Med. Biol. 2017, 959, 93-100.

9. Jorquera, R.; Tanguay, R.M. The mutagenicity of the tyrosine metabolite, fumarylacetoacetate, is enhanced by glutathione depletion. Biochem. Biophys. Res. Commun. 1997, 232, 42-48. [CrossRef]

10. Dawson, C.; Ramachandran, R.; Safdar, S.; Murphy, E.; Swayne, O.; Katz, J.; Newsome, P.N.; Geberhiwot, T. Severe neurological crisis in adult patients with Tyrosinemia type 1. Ann. Clin. Transl. Neurol. 2020, 7, 1732-1737. [CrossRef]

11. Morrow, G.; Tanguay, R.M. Biochemical and clinical aspects of hereditary tyrosinemia type 1. Adv. Exp. Med. Biol. 2017, 959, 9-21. [PubMed]

12. Michals, K.; Matolon, R.; Wong, P.W. Dietary treatment of tyrosinemia type I: Importance of methionine restriction. J. Am. Diet. Assoc. 1978, 73, 507-514. [PubMed]

13. Van Spronsen, F.J; van Rijn, M.; Meyer, U.; Das, A.M. Dietary considerations in tyrosinemia type I. Adv. Exp. Med. Biol. 2017, 959, 197-204. [PubMed]

14. McKiernan, P. Liver transplantation for hereditary tyrosinaemia type 1 in the United Kingdom. Adv. Exp. Med. Biol. 2017, 959, 85-91. [PubMed]

15. Liu, Y.; Luo, Y.; Xia, L.; Qiu, B.J.; Zhou, T.; Feng, M.X.; Xue, F.; Chen, X.S.; Han, L.S.; Zhang, J.J.; et al. Living-donor liver transplantation for children with tyrosinemia type I. J. Dig. Dis. 2020, 21, 189-194. [CrossRef] [PubMed]

16. Karaca, C.A.; Yilmaz, C.; Farajov, R.; Iakobadze, Z.; Aydogdu, S.; Kilic, M. Live donor liver transplantation for type 1 tyrosinemia: An analysis of 15 patients. Pediatr. Transplant. 2019, 23, e13498. [CrossRef]

17. Lindstedt, S.; Holme, E.; Lock, E.A.; Hjalmarson, O.; Strandvik, B. Treatment of hereditary tyrosinaemia type I by inhibition of 4-hydroxyphenylpyruvate dioxygenase. Lancet 1992, 340, 813-817. [CrossRef]

18. Neuckermans, J.; Mertens, A.; De Win, D.; Schwaneberg, U.; De Kock, J. A robust bacterial assay for high-throughput screening of human 4-hydroxyphenylpyruvate dioxygenase inhibitors. Sci. Rep. 2019, 9, 1-11. [CrossRef]

19. Larochelle, J.; Alvarez, F.; Bussières, J.F.; Chevalier, I.; Dallaire, L.; Dubois, J.; Faucher, F.; Fenyves, D.; Goodyer, P.; Grenier, A.; et al. Effect of nitisinone (NTBC) treatment on the clinical course of hepatorenal tyrosinemia in Québec. Mol. Genet. Metab. 2012, 107, 49-54. [CrossRef]

20. Gertsman, I.; Barshop, B.A.; Panyard-Davis, J.; Gangoiti, J.A.; Nyhan, W.L. Metabolic effects of increasing doses of nitisinone in the treatment of alkaptonuria. JIMD Rep. 2015, 24, 13-20.

21. Thimm, E.; Herebian, D.; Assmann, B.; Klee, D.; Mayatepek, E.; Spiekerkoetter, U. Increase of CSF tyrosine and impaired serotonin turnover in tyrosinemia type I. Mol. Genet. Metab. 2011, 102, 122-125. [CrossRef] [PubMed]

22. Davison, A.S.; Harrold, J.A.; Hughes, G.; Norman, B.P.; Devine, J.; Usher, J.; Hughes, A.T.; Khedr, M.; Gallagher, J.A.; Milan, A.M.; et al. Clinical and biochemical assessment of depressive symptoms in patients with Alkaptonuria before and after two years of treatment with nitisinone. Mol. Genet. Metab. 2018, 125, 135-143. [CrossRef] [PubMed]

23. Gertsman, I.; Gangoiti, J.A.; Nyhan, W.L.; Barshop, B.A. Perturbations of tyrosine metabolism promote the indolepyruvate pathway via tryptophan in host and microbiome. Mol. Genet. Metab. 2015, 114, 431-437. [CrossRef] [PubMed]

24. Van Ginkel, W.G.; Jahja, R.; Huijbregts, S.C.J.; Daly, A.; MacDonald, A.; De Laet, C.; Cassiman, D.; Eyskens, F.; Körver-Keularts, I.M.L.W.; Goyens, P.J.; et al. Neurocognitive outcome in tyrosinemia type 1 patients compared to healthy controls. Orphanet J. Rare Dis. 2016, 11, 1-9. [CrossRef]

25. García, M.I.; de la Parra, A.; Arias, C.; Arredondo, M.; Cabello, J.F. Long-term cognitive functioning in individuals with tyrosinemia type 1 treated with nitisinone and protein-restricted diet. Mol. Genet. Metab. Rep. 2017, 11, 12-16. [CrossRef]

26. Tsai, C.P.; Lin, P.Y.; Lee, N.C.; Niu, D.M.; Lee, S.M.; Hsu, W.M. Corneal lesion as the initial manifestation of tyrosinemia type II. J. Chin. Med. Assoc. 2006, 69, 286-288. [CrossRef]

27. Stewart, R.M.K.; Briggs, M.C.; Jarvis, J.C.; Gallagher, J.A.; Ranganath, L. Reversible keratopathy due to hypertyrosinaemia following intermittent low-dose nitisinone in alkaptonuria: A case report. JIMD Rep. 2014, 17, 1-6.

28. Azuma, H.; Paulk, N.; Ranade, A.; Dorrell, C.; Al-Dhalimy, M.; Ellis, E.; Strom, S.; Kay, M.A.; Finegold, M.; Grompe, M. Robust expansion of human hepatocytes in Fah-/-/Rag2-/-/Il2rg-/- mice. Nat. Biotechnol. 2007, 25, 903-910. [CrossRef] 
29. Percie du Sert, N.; Hurst, V.; Ahluwalia, A.; Alam, S.; Avey, M.T.; Baker, M.; Browne, W.J.; Clark, A.; Cuthill, I.C.; Dirnagl, U.; et al. The ARRIVE guidelines 2.0: Updated guidelines for reporting animal research. BMJ Open Sci. 2020, 4, e100115. [CrossRef]

30. Verhulst, S.; Roskams, T.; Sancho-Bru, P.; van Grunsven, L.A. Meta-Analysis of Human and Mouse Biliary Epithelial Cell Gene Profiles. Cells 2019, 8, 1117. [CrossRef]

31. Masurel-Paulet, A.; Poggi-Bach, J.; Rolland, M.O.; Bernard, O.; Guffon, N.; Dobbelaere, D.; Sarles, J.; Ogier de Baulny, H.; Touati, G. NTBC treatment in tyrosinaemia type I: Long-term outcome in French patients. J. Inherit. Metab. Dis. 2008, 31, 81-87. [CrossRef] [PubMed]

32. Aktuglu Zeybek, A.C.; Kiykim, E.; Soyucen, E.; Cansever, S.; Altay, S.; Zubarioglu, T.; Erkan, T.; Aydin, A. Hereditary tyrosinemia type 1 in Turkey: Twenty year single-center experience. Pediatr. Int. 2015, 57, 281-289. [CrossRef] [PubMed]

33. Couce, M.L.; Dalmau, J.; Del Toro, M.; Pintos-Morell, G.; Aldámiz-Echevarría, L. Tyrosinemia type 1 in Spain: Mutational analysis, treatment and long-term outcome. Pediatr. Int. 2011, 53, 985-989. [CrossRef] [PubMed]

34. Cardoso, V.E.S.; Dutra, F.; Soares, C.O.; Alves, A.N.L.; Bevilacqua, E.; Gagioti, S.M.; Penatti, C.A.A.; Bechara, E.J.H. Liver damage induced by succinylacetone: A shared redox imbalance mechanism between tyrosinemia and hepatic porphyrias. J. Braz. Chem. Soc. 2017, 28, 1297-1307. [CrossRef]

35. Lock, E.A.; Gaskin, P.; Ellis, M.K.; McLean Provan, W.; Robinson, M.; Smith, L.L. Tissue distribution of 2-(2-nitro-4trifluoromethylbenzoyl)-cyclohexane-1,3-dione (NTBC) and its effect on enzymes involved in tyrosine catabolism in the mouse. Toxicology 2000, 144, 179-187. [CrossRef]

36. Alobaidy, H.; Barkaoui, E. Experience of a single center in NTBC use in management of hereditary tyrosinemia type I in Libya. Iran. J. Pediatr. 2015, 25, e3608. [CrossRef]

37. Lewerenz, J.; Hewett, S.J.; Huang, Y.; Lambros, M.; Gout, P.W.; Kalivas, P.W.; Massie, A.; Smolders, I.; Methner, A.; Pergande, M.; et al. The cystine/glutamate antiporter system xc- in health and disease: From molecular mechanisms to novel therapeutic opportunities. Antioxid. Redox Signal. 2013, 18, 522-555. [CrossRef]

38. Wang, A.W.; Wangensteen, K.J.; Wang, Y.J.; Zahm, A.M.; Moss, N.G.; Erez, N.; Kaestner, K.H. TRAP-seq identifies cystine/glutamate antiporter as a driver of recovery from liver injury. J. Clin. Investig. 2018, 128, 2297-2309. [CrossRef]

39. Hsu, J.C.; Laz, T.; Mohn, K.L.; Taub, R. Identification of LRF-1, a leucine-zipper protein that is rapidly and highly induced in regenerating liver. Proc. Natl. Acad. Sci. USA 1991, 88, 3511-3515. [CrossRef]

40. Weir, E.; Chen, Q.; Defrances, M.C.; Bell, A.; Taub, R.; Zarnegar, R. Rapid induction of mRNAs for liver regeneration factor and insulin-like growth factor binding protein-1 in primary cultures of rat hepatocytes by hepatocyte growth factor and epidermal growth factor. Hepatology 1994, 20, 955-960. [CrossRef]

41. Hai, T.; Hartman, M.G. The molecular biology and nomenclature of the activating transcription factor/cAMP responsive element binding family of transcription factors: Activating transcription factor proteins and homeostasis. Gene 2001, 273, 1-11. [CrossRef]

42. Nobori, K.; Ito, H.; Tamamori-Adachi, M.; Adachi, S.; Ono, Y.; Kawauchi, J.; Kitajima, S.; Marumo, F.; Isobe, M. ATF3 inhibits doxorubicin-induced apoptosis in cardiac myocytes: A novel cardioprotective role of ATF3. J. Mol. Cell. Cardiol. 2002, 34, 1387-1397. [CrossRef] [PubMed]

43. Allan, A.L.; Albanese, C.; Pestell, R.G.; LaMarre, J. Activating Transcription Factor 3 Induces DNA Synthesis and Expression of Cyclin D1 in Hepatocytes. J. Biol. Chem. 2001, 276, 27272-27280. [CrossRef] [PubMed]

44. Yin, X.; DeWille, J.W.; Hai, T. A potential dichotomous role of ATF3, an adaptive-response gene, in cancer development. Oncogene 2008, 27, 2118-2127. [CrossRef] [PubMed]

45. Jun, J.I.; Lau, L.F. Taking aim at the extracellular matrix: CCN proteins as emerging therapeutic targets. Nat. Rev. Drug Discov. 2011, 10, 945-963. [CrossRef] [PubMed]

46. Leitinger, B. Discoidin domain receptor functions in physiological and pathological conditions. Int. Rev. Cell Mol. Biol. 2014, 310, 39-87.

47. Moll, S.; Desmoulière, A.; Moeller, M.J.; Pache, J.C.; Badi, L.; Arcadu, F.; Richter, H.; Satz, A.; Uhles, S.; Cavalli, A.; et al. DDR1 role in fibrosis and its pharmacological targeting. Biochim. Biophys. Acta Mol. Cell Res. 2019, 1866, 118474. [CrossRef]

48. Kiamehr, M.; Heiskanen, L.; Laufer, T.; Düsterloh, A.; Kahraman, M.; Käkelä, R.; Laaksonen, R.; Aalto-Setälä, K. Dedifferentiation of primary hepatocytes is accompanied with reorganization of lipid metabolism indicated by altered molecular lipid and miRNA profiles. Int. J. Mol. Sci. 2019, 20, 2910. [CrossRef]

49. Yoon, S.M.; Gerasimidou, D.; Kuwahara, R.; Hytiroglou, P.; Yoo, J.E.; Park, Y.N.; Theise, N.D. Epithelial cell adhesion molecule (EpCAM) marks hepatocytes newly derived from stem/progenitor cells in humans. Hepatology 2011, 53, 964-973. [CrossRef]

50. Safarikia, S.; Carpino, G.; Overi, D.; Cardinale, V.; Venere, R.; Franchitto, A.; Onori, P.; Alvaro, D.; Gaudio, E. Distinct EpCAMPositive Stem Cell Niches Are Engaged in Chronic and Neoplastic Liver Diseases. Front. Med. 2020, 7, 479. [CrossRef]

51. Yamashita, T.; Ji, J.; Budhu, A.; Forgues, M.; Yang, W.; Wang, H.Y.; Jia, H.; Ye, Q.; Qin, L.X.; Wauthier, E.; et al. EpCAM-Positive Hepatocellular Carcinoma Cells Are Tumor-Initiating Cells with Stem/Progenitor Cell Features. Gastroenterology 2009, 136, 1012-1024. [CrossRef] [PubMed]

52. Dimitri, P.; Habeb, A.M.; Garbuz, F.; Millward, A.; Wallis, S.; Moussa, K.; Akcay, T.; Taha, D.; Hogue, J.; Slavotinek, A.; et al. Expanding the clinical spectrum associated with GLIS3 mutations. J. Clin. Endocrinol. Metab. 2015, 100, E1362-E1369. [CrossRef] [PubMed] 
53. Wolf, J.H.; Bhatti, T.R.; Fouraschen, S.; Chakravorty, S.; Wang, L.; Kurian, S.; Salomon, D.; Olthoff, K.M.; Hancock, W.W.; Levine, M.H. Heat shock protein 70 is required for optimal liver regeneration after partial hepatectomy in mice. Liver Transpl. 2014, 20, 376-385. [CrossRef] [PubMed]

54. Wilmes, A.; Limonciel, A.; Aschauer, L.; Moenks, K.; Bielow, C.; Leonard, M.O.; Hamon, J.; Carpi, D.; Ruzek, S.; Handler, A.; et al. Application of integrated transcriptomic, proteomic and metabolomic profiling for the delineation of mechanisms of drug induced cell stress. J. Proteom. 2013, 79, 180-194. [CrossRef]

55. Lin, S.; Qiao, N.; Chen, H.; Tang, Z.; Han, Q.; Mehmood, K.; Fazlani, S.A.; Hameed, S.; Li, Y.; Zhang, H. Integration of transcriptomic and metabolomic data reveals metabolic pathway alteration in mouse spermatogonia with the effect of copper exposure. Chemosphere 2020, 256, 126974. [CrossRef]

56. Zhu, M.; Li, L.; Lu, T.; Yoo, H.; Zhu, J.; Gopal, P.; Wang, S.C.; Porembka, M.R.; Rich, N.E.; Kagan, S.; et al. Uncovering Biological Factors That Regulate Hepatocellular Carcinoma Growth Using Patient-Derived Xenograft Assays. Hepatology 2020, 72, $1085-1101$. [CrossRef] 